\title{
The distribution of axial length, anterior chamber depth, lens thickness, and vitreous chamber depth in an adult population of Shahroud, Iran
}

Hassan Hashemi ${ }^{1,2}$, Mehdi Khabazkhoob', Mohammad Miraftab', Mohammad Hassan Emamian³, Mohammad Shariati ${ }^{4}$, Tahereh Abdolahinia ${ }^{1,5}$ and Akbar Fotouhi ${ }^{6 *}$

\begin{abstract}
Background: Ocular biometric parameters can be influenced by race, ethnicity, and genetics; their differences across different populations can probably explain differences in refractive errors in these populations. The aim of this study is to determine the normal range of axial length, anterior chamber depth, lens thickness, and vitreous chamber depth in the population of Shahroud in the north of Iran.
\end{abstract}

Methods: In the first phase of Shahroud Eye Cohort Study, the 40-64 year old population were sampled cross-sectionally; 6311 were invited and 5190 (82.2\%) participated in the study. Biometric examinations were done using the LENSTAR/BioGraph (WaveLight AG, Erlangen, Germany) after vision tests and before cycloplegic refraction tests. Any type of eye surgery, extensive pterygium, and lack of cooperation were used as exclusion criteria, and analyses were done with data from 4869 eyes.

Results: We found a mean axial length of $23.14 \mathrm{~mm}$ (95\% confidence interval [Cl], 23.11-23.17), mean anterior chamber depth of $2.62 \mathrm{~mm}(95 \% \mathrm{Cl}, 2.60-2.63)$, mean lens thickness of $4.28 \mathrm{~mm}(95 \% \mathrm{Cl}, 4.27-4.29)$, and the mean vitreous chamber depth was $15.72 \mathrm{~mm}$ (95\% Cl, 15.70-15.75).

Kolmogorov-Smirnov tests showed that the distribution of axial length, anterior chamber depth, lens thickness, and vitreous chamber depth significantly differed from normal; axial length and vitreous chamber depth demonstrated a leptokurtic distribution as well.

Axial length, anterior chamber depth, and vitreous chamber depth significantly decreased with age, and lens thickness significantly increased with age $(p<0.001)$. All indices were significantly higher in men.

Conclusions: The distributions of axial length, vitreous chamber depth, and lens thickness are reported for the first time in an Iranian adult population. Compared to other studies, axial length was in the mid range, nonetheless, studying axial length components showed that the Iranian population had smaller anterior chamber depth and lens thickness. Age and gender were significantly associated with all indices assessed in this study.

Keywords: Axial length- Anterior chamber depth lens thickness- Vitreous chamber depth, Normal range

\footnotetext{
*Correspondence: afotouhi@tums.ac.ir

${ }^{6}$ Department of Epidemiology and Biostatistics, School of Public Health,

Tehran University of Medical Sciences, Tehran, Iran

Full list of author information is available at the end of the article
} 


\section{Background}

Global advances in ophthalmology have created a greater need for ocular parameters in different clinical and diagnostic fields. One important ophthalmic parameter is the axial length (AL) which is commonly needed for intraocular lens power calculation before cataract and refractive surgery [1] and helps ophthalmologists in the diagnosis of several eye conditions such as staphyloma, [2] and risk of retinal detachment [3].

In addition to clinical applications, determining ocular biometry, especially the $\mathrm{AL}$ and its components in epidemiologic studies, provides ophthalmologists with important and valuable information. Reports concerning the distribution of ocular biometrics in population based studies have been published from some Asian countries such as Mongolia, Taiwan, Myanmar, Singapore and China [4-8].

Several studies have demonstrated the correlation between ocular biometrics, especially AL, with refractive errors $[6,9]$. Since these parameters can be influenced by race, ethnicity, and genetics, their differences across different populations can probably explain differences in refractive errors, and it would be useful to determine the distribution of biometric indices in each area.

There are few studies on the distribution of biometrics, especially axial length, in normal populations in the Middle East region and Iran $[9,10]$. As a populationbased study, the report from Saudi Arabia [10] has the limitation of a small sample size. The study on Jordanian adults [9] only targeted the 17 to 40 year old population, and the study by Yekta et al. [11] in Iran showed ocular biometrics in carpet weavers where a considerable proportion were myopic and their results cannot be generalized to the normal population. Here we report the distribution of AL and its components including the anterior chamber depth (ACD), lens thickness (LT), and vitreous chamber depth (VCD) in a general 40-64 year old Iranian population.

\section{Methods}

Data of the present study was derived from the first phase of the Shahroud eye cohort study, which was conducted cross-sectionally in 2009. In brief, samples of the study were selected from the 40-64 year old population of Shahroud using random cluster sampling where 300 clusters from 9 strata (health care centers) of Shahroud city were randomly selected. From each cluster, 20 people were invited to have complete eye examinations.

At the time of the 2006 census, the population of Shahroud was 133835. Of these, 28779 were in the 4064 year old age group; $14720(51.1 \%)$ of which were men. In this group, $29.0 \%$ were $40-44$ years old, $26.8 \%$ were between 45 and 49 years of age, $20.3 \%$ were $50-55$, $13.8 \%$ were $55-59$, and $10.1 \%$ were between 60 and 64 years old. In this study, 6311 people were selected from this population.

All consenting participants were first interviewed to record their demographics, socio-economic status, as well as their medical and ophthalmic history. For ophthalmologic examinations, people were examined with the slit lamp biomicroscope, and if no contraindication existed for cyclopentolate eye drops, they had cycloplegic refraction tests.

\section{Biometry}

All participants had ocular biometry tests with the LENSTAR/BioGraph (WaveLight AG, Erlangen, Germany) after vision testing and before ophthalmologic examination and cycloplegic refraction. The Biograph generates different ocular biometry indices and here the AL, ACD, LT, and corneal thickness readings were used. Acquisitions were done by a skilled operator who was trained before the study. The validity and repeatability of LENSTAR/BioGraph measurements have been confirmed before [12,13], and thus, one acquisition was made per eye.

Table 1 Distribution of axial length (AL), anterior chamber depth (ACD), lens thickness (LT) and vitreous chamber depth (VCD) as mean and $95 \%$ confidence intervals of mean $(\mathrm{CI})$ by age and gender

\begin{tabular}{|c|c|c|c|c|c|}
\hline & & $\mathrm{AL}(\mathrm{mm})$ & $\mathrm{ACD}(\mathrm{mm})$ & $\mathrm{LT}(\mathrm{mm})$ & VCD $(\mathrm{mm})$ \\
\hline Age & $\mathbf{n}$ & Mean $(95 \% \mathrm{Cl})$ & Mean $(95 \% \mathrm{Cl})$ & Mean $(95 \% \mathrm{Cl})$ & Mean $(95 \% \mathrm{Cl})$ \\
\hline $40-44$ & 917 & $23.24(23.17-23.30)$ & $2.74(2.72-2.76)$ & $4.11(4.09-4.13)$ & 15.86 (15.80-15.93) \\
\hline 45-49 & 1332 & $23.16(23.11-23.21)$ & $2.66(2.65-2.68)$ & $4.22(4.20-4.23)$ & 15.75 (15.70-15.80) \\
\hline $50-54$ & 1218 & $23.16(23.10-23.21)$ & $2.60(2.58-2.62)$ & $4.31(4.30-4.33)$ & $15.72(15.67-15.78)$ \\
\hline $55-59$ & 880 & $23.07(23.00-23.13)$ & $2.52(2.50-2.54)$ & $4.39(4.37-4.41)$ & 15.63 (15.57-15.70) \\
\hline $60-64$ & 522 & $23.04(22.96-23.12)$ & $2.48(2.45-2.51)$ & $4.47(4.44-4.50)$ & 15.56 (15.49-15.64) \\
\hline \multicolumn{6}{|l|}{ Gender } \\
\hline Male & 2044 & $23.41(23.37-23.46)$ & $2.66(2.64-2.67)$ & $4.30(4.29-4.32)$ & 15.93 (15.89-15.97) \\
\hline Female & 2825 & $22.95(22.91-22.98)$ & $2.58(2.57-2.60)$ & $4.26(4.25-4.27)$ & 15.58 (15.54-15.61) \\
\hline Total & 4869 & $23.14(23.11-23.17)$ & $2.62(2.60-2.63)$ & $4.28(4.27-4.29)$ & 15.72 (15.70-15.75) \\
\hline Valid data & & 4833 & 4849 & 4840 & 4823 \\
\hline
\end{tabular}


Table 2 The range (mean \pm 2 standard deviations) of axial length $(A L)$, anterior chamber depth $(A C D)$, lens thickness (LT) and vitreous chamber depth (VCD) by age and gender

\begin{tabular}{lllll}
\hline Age & AL $(\mathbf{m m})$ & ACD $(\mathbf{m m})$ & LT $(\mathbf{m m})$ & VCD $(\mathbf{m m})$ \\
\hline $\mathbf{4 0 - 4 4}$ & $21.29-25.19$ & $2.12-3.35$ & $3.59-4.63$ & $14.02-17.71$ \\
\hline $\mathbf{4 5 - 4 9}$ & $21.25-25.07$ & $2.02-3.31$ & $3.69-4.75$ & $13.96-17.54$ \\
\hline $\mathbf{5 0 - 5 4}$ & $21.22-25.10$ & $1.97-3.23$ & $3.76-4.86$ & $13.90-17.55$ \\
\hline $\mathbf{5 5 - 5 9}$ & $21.05-25.08$ & $1.86-3.18$ & $3.83-4.95$ & $13.75-17.52$ \\
\hline $\mathbf{6 0 - 6 4}$ & $21.17-24.91$ & $1.81-3.15$ & $3.87-5.07$ & $13.76-17.36$ \\
\hline Male & $21.06-24.84$ & $1.93-3.24$ & $3.68-4.85$ & $13.77-17.38$ \\
\hline Female & $21.53-25.30$ & $1.99-3.33$ & $3.71-4.90$ & $14.14-17.72$ \\
\hline Total & $21.20-25.09$ & $1.95-3.28$ & $3.69-4.87$ & $13.89-17.56$ \\
\hline
\end{tabular}

\section{Definitions and statistical analysis}

Since VCD is not measured directly with the Biograph, $\mathrm{ACD}$, LT, and corneal thickness $(\mathrm{mm})$ values were deducted from AL to calculate VCD. Each ocular biometry index is described as mean and 95\% confidence intervals $(\mathrm{CI})$ by age and gender, and the normal range calculated as the mean \pm 2 standard deviations. the $25^{\text {th }}$, $50^{\text {th }}, 75^{\text {th }}, 95^{\text {th }}$ and $99^{\text {th }}$ percentiles were determined to demonstrate the distribution of these variables in more detail. The relationship of AL and its components with age, gender, height, weight, and education was studied with univariate linear regression, as well as with multivariate regression after adjusting variables. The t-test was used to compare the mean age of the participants and non-participants, and the chi-square test was used to examine differences in gender distribution between the selected sample and the respondents. To assess distribution differences from normal, distributions were plotted on histograms after using the KolmogorovSmirnov test. Pearson correlation coefficients were determined to examine the correlation between two eyes in terms of $\mathrm{AL}$ and its components.

In this report, only data from phakic eyes were included for analysis, and those who had any history of eye surgery were excluded. The correlation between left and right eyes was high in case of the indices of AL $(r=0.880), A C D$ $(r=0.958)$, LT $(r=0.880)$, and VCD $(r=0.931)$, and thus, only results from right eyes and presented here.

\section{Ethical considerations}

Before examinations, and after providing a detailed description of the study and its methodology, all participants signed written informed consents. The study was reviewed and approved by the Ethics Committee of Shahroud University of Medical Sciences.

\section{Results}

The invitees of Shahroud Eye Cohort Study were 6311 people and 5190 responded (82.2\%). The mean age of the participants and non-participants was 50.9 years and 50.6 years, respectively, and their difference was not statistically significant $(\mathrm{p}=0.160)$.

Of the participants, we excluded 151 people due to history of ocular surgery or history of ocular trauma (115 people cataract surgery, 7 people glaucoma surgery, 8 people retinal surgery, and 21 people due to a history of ocular trauma). Data of 170 people was not considered due to lack of cooperation, presence of extensive pterygium, or receiving an error message from the device. Eventually, analysis was done on 4869 eyes. Of this sample, 2825 (58\%) were women; 97.6\% were of Persian ethnicity, $2.0 \%$ were Turk, and $0.4 \%$ were non-Persian and non-Turk although none of the ethnic groups are a different race and all considered Middle Eastern.

In the studied sample, mean AL was $23.14 \mathrm{~mm}$ (95\% CI, 23.11 - 23.17), mean ACD was $2.62 \mathrm{~mm}$ (95\% CI, 2.60 2.63), mean LT was $4.28 \mathrm{~mm}(95 \% \mathrm{CI}, 4.27-4.29)$, and the mean VCD was $15.72 \mathrm{~mm}$ (95\% CI, 15.70 - 15.75).

Results in terms of mean and 95\% CI of mean of the AL, ACD, LT, and VCD in the studied population by age and gender, the mean \pm 2 SD of these variables by age and gender, and the $1^{\text {th }}, 5^{\text {th }}, 25^{\text {th }}, 50^{\text {th }}, 95^{\text {th }}$ and $99^{\text {th }}$ percentiles of these variables are summarized in Tables 1,2 , and 3, respectively. Figure 1 shows the histogram of the distribution of AL, ACD, LT, and VCD. KolmogorovSmirnov tests indicated a significant difference from normal distribution $(\mathrm{p}<0.001)$. Table 3 summarizes the skewness and kurtosis of the variables. According to indices of normal distribution, axial length and vitreous chamber depth had leptokurtic distribution.

The relationship of studied variables with age, gender, education, height, and weight was studied in univariate

Table 3 The percentiles, Skewness, Kurtosis and interquartile range (IQR) of axial length, anterior chamber depth, vitreous chamber depth and lens thickness in this study

\begin{tabular}{|c|c|c|c|c|c|c|c|c|c|c|}
\hline & \multicolumn{7}{|c|}{ Percentile } & \multicolumn{3}{|c|}{ Normal distribution indexes } \\
\hline & $1 \%$ & $5 \%$ & $25 \%$ & $50 \%$ & $75 \%$ & $95 \%$ & $99 \%$ & Skewness & Kurtosis & IQR \\
\hline Axial length & 21.06 & 21.72 & 22.55 & 23.08 & 23.65 & 24.64 & 26.11 & 1.18 & 5.93 & 1.10 \\
\hline Anterior chamber depth & 1.85 & 2.08 & 2.39 & 2.61 & 2.84 & 3.17 & 3.41 & 0.10 & 0.02 & 0.45 \\
\hline Lens thickness & 3.63 & 3.80 & 4.08 & 4.27 & 4.47 & 4.77 & 5.01 & 0.17 & 0.21 & 0.39 \\
\hline Vitreous chamber depth & 13.78 & 14.42 & 15.17 & 15.66 & 16.20 & 17.16 & 18.52 & 1.24 & 6.32 & 1.03 \\
\hline
\end{tabular}



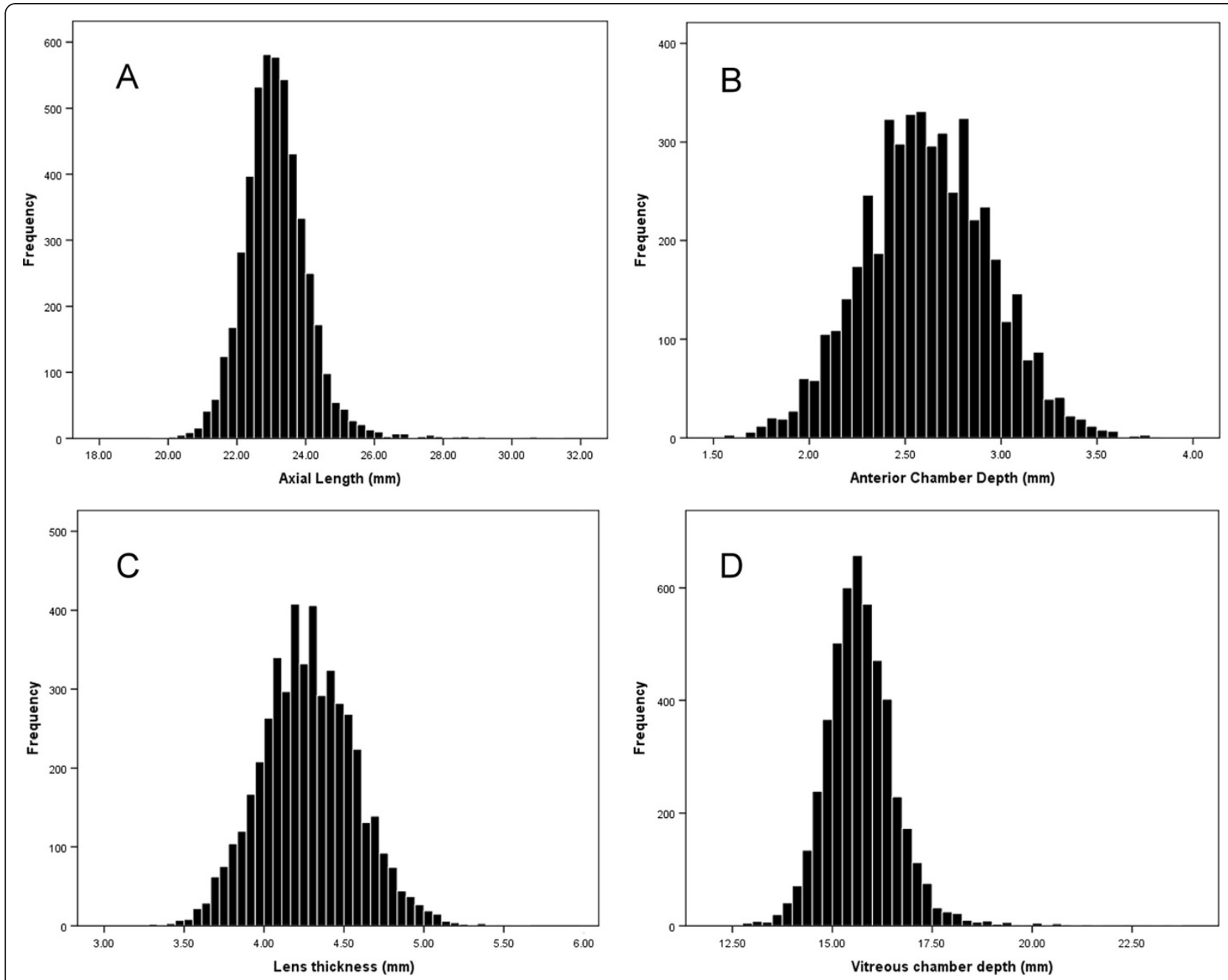

Figure 1 Distribution of axial length (A), anterior chamber depth (B), lens thickness C), and vitreous chamber depth (D).

and multivariate regression models and results are summarized in Tables 4 and 5. According to the multivariate model, AL decreased with age, and directly correlated with the male gender, years of education, height, and weight. ACD also decreased by $0.013 \mathrm{~mm}$ per year of aging, and directly correlated with the male gender, years of education, height, and weight. This is while LT increased by $0.018 \mathrm{~mm}$ per year of aging; it was, on average, $0.026 \mathrm{~mm}$ larger in men compared to women, and the correlation with education and weight was reverse. VCD showed a statistically significant decrease of $0.011 \mathrm{~mm}$ per year while it significantly increased with more education, height, and weight.

\section{Discussion}

AL has different applications in ophthalmology, and so, we used various statistical indices such as the $95 \% \mathrm{CI}$, normal range, and percentiles to describe the distribution of these variables. Describing the normal range of this index can be important in the choice of formula used for intraocular lens calculation in cataract patients. The distribution of AL in the normal population in Iran has not been studied, but according to other studies (Table 6) AL varies between $22.6 \mathrm{~mm}$ to $24.09 \mathrm{~mm}$, and the mean AL in our study falls in the midrange. The first reason for this variation could be the age range of samples, because as demonstrated here and in other studies $[6,14]$, AL decreases with age, and in Table 6, the highest $\mathrm{AL}$ is seen in the 17-30 year old age group, and the lowest $\mathrm{AL}$ value belongs to over 70 year olds. Comparison of AL in people over 40 years in different regions shows that the index varies between $22.6 \mathrm{~mm}$ to $23.6 \mathrm{~mm}$ in this age group. On one hand, Warrier et al. [6] reported a mean $\mathrm{AL}$ of $22.75 \mathrm{~mm}$ in 60 to 69 year olds, while the 59 to 64 year old group in the study by Fotedar et al. [14] had a mean AL of $23.60 \mathrm{~mm}$. Overall, much of these differences can be explained by racial and genetic differences [15]. The direct relationship between AL and 
Table 4 The association of axial length and its components with age and gender according to univariate linear regression

\begin{tabular}{|c|c|c|c|}
\hline & & Coefficient ( $95 \% \mathrm{Cl}$ of coefficient) & P-value \\
\hline \multirow[t]{5}{*}{ Axial length (mm) } & Age (years) & $-0.010(-0.015$ to -0.006$)$ & $<0.001$ \\
\hline & Sex (male/female) & 0.466 (0.41 to 0.522$)$ & $<0.001$ \\
\hline & Education (Each year in school) & $0.026(0.021$ to 0.031$)$ & $<0.001$ \\
\hline & Height (cm) & 0.033 (0.03 to 0.036$)$ & $<0.001$ \\
\hline & Weight (Kg) & 0.013 (0.01 to 0.015$)$ & $<0.001$ \\
\hline \multirow[t]{5}{*}{ Anterior Chamber depth (mm) } & Age (years) & $-0.014(-0.015$ to -0.012$)$ & $<0.001$ \\
\hline & Sex (male/female) & 0.076 (0.057 to 0.095$)$ & $<0.001$ \\
\hline & Education (Each year in school) & 0.008 (0.006 to 0.01$)$ & $<0.001$ \\
\hline & Height (cm) & $0.007(0.006-0.008)$ & $<0.001$ \\
\hline & Weight (Kg) & 0.004 (0.003 to 0.005$)$ & $<0.001$ \\
\hline \multirow[t]{5}{*}{ Lens thickness $(\mathrm{mm})$} & Age (years) & 0.018 (0.017 to 0.02) & $<0.001$ \\
\hline & Sex (male/female) & 0.040 (0.024 to 0.057$)$ & $<0.001$ \\
\hline & Education (Each year in school) & $-0.005(-0.007$ to -0.003$)$ & $<0.001$ \\
\hline & Height (cm) & $0.00(-0.001$ to 0.001$)$ & 0.678 \\
\hline & Weight (Kg) & $-0.002(-0.002$ to -0.001$)$ & $<0.001$ \\
\hline \multirow[t]{5}{*}{ Vitreous chamber depth (mm) } & Age (years) & $-0.015(-0.019$ to -0.01$)$ & $<0.001$ \\
\hline & Sex (male/female) & 0.351 (0.299 to 0.403$)$ & $<0.001$ \\
\hline & Education (Each year in school) & 0.022 (0.017 to 0.027$)$ & $<0.001$ \\
\hline & Height $(\mathrm{cm})$ & 0.027 (0.024 to 0.03$)$ & $<0.001$ \\
\hline & Weight (Kg) & 0.01 (0.008 to 0.012$)$ & $<0.001$ \\
\hline
\end{tabular}

$\mathrm{Cl}=$ confidence interval.

Table 5 The association between axial length and its parameters with age and gender in multivariate linear regressions

\begin{tabular}{|c|c|c|c|}
\hline & & Coefficient ( $95 \% \mathrm{Cl}$ of coefficient) & P-value \\
\hline \multirow[t]{5}{*}{ Axial length $(\mathrm{mm})$} & Age (years) & $-0.007(-0.012$ to -0.003$)$ & $<0.001$ \\
\hline & Sex (male/female) & 0.111 (0.035 to 0.186$)$ & 0.004 \\
\hline & Education (Each year in school) & 0.011 (0.005 to 0.016$)$ & $<0.001$ \\
\hline & Height $(\mathrm{cm})$ & 0.025 (0.021 to 0.029$)$ & $<0.001$ \\
\hline & Weight (Kg) & 0.005 (0.003 to 0.007$)$ & $<0.001$ \\
\hline \multirow[t]{5}{*}{ Anterior Chamber depth (mm) } & Age (years) & $-0.013(-0.014$ to -0.012$)$ & $<0.001$ \\
\hline & Sex (male/female) & $0.038(0.012$ to 0.064$)$ & 0.004 \\
\hline & Education (Each year in school) & $0.004(0.002$ to 0.005$)$ & $<0.001$ \\
\hline & Height (cm) & 0.003 (0.002 to 0.004$)$ & $<0.001$ \\
\hline & Weight (Kg) & 0.002 (0.002 to 0.003$)$ & $<0.001$ \\
\hline \multirow[t]{5}{*}{ Lens thickness $(\mathrm{mm})$} & Age (years) & 0.018 (0.017 to 0.019$)$ & $<0.001$ \\
\hline & Sex (male/female) & 0.026 (0.01 to 0.043 ) & $<0.001$ \\
\hline & Education (Each year in school) & $-0.002(-0.004$ to -0.001$)$ & 0.005 \\
\hline & Height $(\mathrm{cm})$ & & NS \\
\hline & Weight (Kg) & $-0.001(-0.002$ to -0.001$)$ & $<0.001$ \\
\hline \multirow[t]{5}{*}{ Vitreous chamber depth (mm) } & Age (years) & $-0.011(-0.015$ to -0.007$)$ & $<0.001$ \\
\hline & Sex (male/female) & & NS \\
\hline & Education (Each year in school) & 0.009 (0.004 to -0.014$)$ & $<0.001$ \\
\hline & Height $(\mathrm{cm})$ & $0.023(0.021$ to -0.026$)$ & $<0.001$ \\
\hline & $\overline{\text { Weight (Kg) }}$ & 0.004 (0.001 to -0.006$)$ & $<0.001$ \\
\hline
\end{tabular}


Table 6 Mean axial length, anterior chamber depth, lens thickness, and vitreous chamber depth reported in population-based studies compared to findings of the present study

\begin{tabular}{|c|c|c|c|c|c|c|}
\hline Author & Age (Year) & Place & $\mathrm{AL}(\mathrm{mm})$ & $\mathrm{ACD}(\mathrm{mm})$ & LT (mm) & $\operatorname{VCD}(\mathrm{mm})$ \\
\hline Wong [7] & 40 to 81 & Singapore & 23.23 & 2.90 & 4.75 & 15.58 \\
\hline Wickremasinghe[4] & $40-49$ & Mongolia & 23.2 & 3.0 & 4.2 & 16.0 \\
\hline Wickremasinghe[4] & $50-59$ & Mongolia & 23.2 & 2.8 & 4.4 & 16.0 \\
\hline Wickremasinghe[4] & $60-69$ & Mongolia & 23.3 & 2.7 & 4.5 & 16.0 \\
\hline Wickremasinghe[4] & $>70$ & Mongolia & 23.3 & 2.6 & 4.6 & 16.0 \\
\hline Warrier[6] & $40-49$ & Myanmar & 22.75 & 3.03 & 4.31 & 15.41 \\
\hline Warrier[6] & $50-59$ & Myanmar & 22.74 & 2.84 & 4.51 & 15.39 \\
\hline Warrier[6] & $60-69$ & Myanmar & 22.75 & 2.76 & 4.59 & 15.40 \\
\hline Warrier[6] & $>70$ & Myanmar & 22.73 & 2.69 & 4.63 & 15.41 \\
\hline Warrier[6] & $40+$ & Myanmar & 22.76 & 2.82 & 4.51 & 15.43 \\
\hline Shufelt[19] & $40+$ & United State & 23.38 & 3.41 & 4.38 & 15.04 \\
\hline Fotedar[14] & $59-64$ & Australia & 23.60 & 3.20 & - & - \\
\hline Fotedar[14] & $65-74$ & Australia & 23.44 & 3.13 & - & - \\
\hline Fotedar[14] & $75-84$ & Australia & 23.39 & 3.05 & - & - \\
\hline Fotedar[14] & $85+$ & Australia & 23.23 & 2.89 & - & - \\
\hline Jivrajka[20] & 29-95 & United State & 23.46 & 2.96 & 4.93 & - \\
\hline $\mathrm{He}[8]$ & $50-59$ & China & 23.08 & 2.79 & 4.26 & - \\
\hline $\mathrm{He}[8]$ & $60-69$ & China & 23.14 & 2.65 & 4.47 & - \\
\hline $\mathrm{He}[8]$ & $70-79$ & China & 23.08 & 2.60 & 4.64 & - \\
\hline $\mathrm{He}[8]$ & 80-93 & China & 23.11 & 2.57 & 4.65 & - \\
\hline $\mathrm{He}[8]$ & All age & China & 23.11 & 2.67 & 4.44 & - \\
\hline Velez-Montoya[21] & $54.71 \pm 22.33$ & Mexico & 23.33 & 3.25 & 4.52 & - \\
\hline This study & $40-64$ & Iran & 23.14 & 2.62 & 4.28 & 15.72 \\
\hline
\end{tabular}

$\mathrm{AL}=$ Axial length.

$\mathrm{ACD}=$ Anterior chamber depth .

$\mathrm{LT}=$ Lens thickness.

VCD $=$ Vitreous chamber depth

height has been demonstrated in previous studies as well, [16-18] and this relationship can explain part of the differences seen in samples and populations of different heights. Environmental and life style factors, such as industrialization, which can influence the rate of near work, should be considered as well.

Mean ACD in this study was $2.62 \mathrm{~mm}$. As demonstrated in Table 6 , the value ranges between 2.57 and $3.41 \mathrm{~mm}$. XU et al. [22] showed this value to be $2.42 \mathrm{~mm}$ in over 45 year old Chinese, and overall, the over 40 year olds in different studies have about $1 \mathrm{~mm}$ difference in ACD; lower in Asians, especially in Eastern Asians, and the highest in Los Angeles Latinos. Mean ACD in this study was relatively low. A similar observation was made in the Tehran Eye Study [23] where the mean ACD in the over 40 year old age group was between 2.50 to $2.69 \mathrm{~mm}$, thus, we can hypothesize that the people of Iran have short anterior chambers. Also, considering the observations in the Chinese and Mongolians compared to Americans, the ACD can be assumed smaller in Asians.
The LT in the studied population was lower compared to available studies. (Table 6) In contrast to ACD, our findings on LT were very similar to that in Americans, and considerably lower than that in Eastern Asians, especially the Chinese. However, the variation in LT in different studies is overall less than that with ACD.

In this study, AL, ACD, and VCD shortened with age, and lens thickness increased. A similar association has been reported by He et al. [24], Foster et al. [25], Fotedar et al. [14] Jivrajka et al. [20], and Warrier et al. [6]. Although an increase in AL is expectable from infancy until adolescence, [26] it is difficult to explain the shortening of the eye after middle age years. Our first impression was that we could bring up the age cohort effect, but Gudmundsdottir et al. [27] demonstrated AL shortening in a 5 year cohort study; this finding weakens the age cohort effect hypothesis, and it seems that the AL may decrease with age due to some unknown changes, especially ocular atrophy. It must also be noted that our data come from a cross-sectional study, therefore no judgment can be made about the trend of AL changes 
Table 7 Summary of some other studies concerning the association of studied parameters with gender

\begin{tabular}{|c|c|c|c|c|c|}
\hline Place & Age & $\mathrm{AL}(\mathrm{mm})$ & ACD (mm) & LT (mm) & $\operatorname{VCD}(\mathrm{mm})$ \\
\hline \multirow[t]{2}{*}{ Myanmar[6] } & $40+$ & $\mathrm{M}: 23.12$ & M: 2.86 & M:4.52 & M: 15.74 \\
\hline & & $F: 22.54$ & $F: 2.79$ & $F: 4.5$ & $F: 15.24$ \\
\hline \multirow[t]{2}{*}{ Jordan[9] } & $17-40$ & M:23.33 & M: 3.17 & M:3.89 & M: 16.2 \\
\hline & & F: 22.29 & $F: 3.21$ & $F: 3.83$ & F:15.93 \\
\hline \multirow[t]{2}{*}{ United State[19] } & $40+$ & M:23.65 & M: 3.48 & M:4.40 & M: 15.22 \\
\hline & & F: 23.18 & $F: 3.36$ & $F: 4.3$ & $F: 14.91$ \\
\hline \multirow[t]{2}{*}{ Reykjavik[36] } & $55+$ & $\mathrm{M}: 23.74$ & M: 3.20 & M:4.68 & \\
\hline & & F: 23.20 & $F: 3.08$ & $F: 4.65$ & \\
\hline \multirow[t]{2}{*}{ Australia[14] } & $59+$ & M:23.75 & M: 3.16 & & \\
\hline & & F: 23.20 & $F: 3.06$ & & \\
\hline \multirow[t]{2}{*}{ Norfolk, UK[18] } & $48-88$ & $\mathrm{M}: 23.80$ & M: 3.15 & & \\
\hline & & F: 23.29 & $F: 3.08$ & & \\
\hline \multirow[t]{2}{*}{ China[8] } & $50+$ & $\mathrm{M}: 23.38$ & M: 2.75 & M:4.32 & \\
\hline & & F: 22.83 & $F: 2.61$ & $F: 4.50$ & \\
\hline \multirow[t]{2}{*}{ Mongolia[4] } & $40+$ & M:23.43 & M: 2.87 & & \\
\hline & & F: 23.08 & $F: 2.77$ & & \\
\hline \multirow[t]{2}{*}{ This study } & $40-64$ & M:23.41 & M:2.66 & M:4.30 & M:15.93 \\
\hline & & $F: 22.95$ & $F: 2.58$ & $F: 4.26$ & $F: 15.58$ \\
\hline
\end{tabular}

$\mathrm{AL}=$ Axial length

$A C D=$ Anterior chamber depth.

$\mathrm{LT}=$ Lens thickness.

$\mathrm{VCD}=$ Vitreous chamber depth

$M=$ male.

$\mathrm{F}=$ female

with age and longitudinal studies are needed for a definite answer.

A decrease in ACD and increase in LT with age is another finding of this study as well as other studies $[24,25]$.An increase in LT has been observed by Mallen et al. [9] between the ages of 17 and 40 years, as well. It has also been observed by Koretz et al. [28] in monkeys. The increase in LT with age can be attributed to the increase in protein fiber layers forming under the capsule. As mentioned, the ACD decreases with age, and in this regard, the increase in LT can be the main cause for the decrease in ACD, and this has been stated in the report by Praveen et al. [29].

All of the assessed biometrics in this study were greater in men. Results of some studies concerning these findings are shown in Table 7; all studies demonstrated higher AL and ACD values in men, while the association between LT and gender has contradicting results, and even in the study by $\mathrm{He}$ et al. [8], this value is reported greater in women. In studies where the VCD is assessed, this index is reported higher in men. Based on these findings, inter-gender differences in refractive errors are expected. However, most studies have demonstrated a flatter corneal curvature in men $[6,8,19]$ and although a flatter cornea can decrease part of the myopic shift of the refraction in men, most studies have shown more myopia in men [30-32] and more hyperopia in women [33]. There seems to be a more prominent role for $\mathrm{AL}$ in the inter-gender difference in refractive errors compared to other ocular biometrics.

This study has limitations and strengths. Since detailed results with refractive errors have already been published, [34] they are not presented here. Unlike previous studies in Iran, [32,35] myopia (with the prevalence of $38.3 \%$ ) was more prevalent than hyperopia (with the prevalence of $22.1 \%$ ) in this population.

Although mean AL in this sample was in the midrange compared to other studies, but as demonstrated, this index was slightly skewed to right and had a leptokurtic distribution, and thus, part of the high prevalence of myopia in the 40-64 year old population of Shahroud could be attributed to the non-normal distribution of $\mathrm{AL}$ in this population.

The most important strong point is that $\mathrm{AL}$ and its components are studied in a large sample size of 40 to 64 year old adults, which is unprecedented. It provides valuable information from a normal Iranian sample which can add to our knowledge of the Middle Eastern population. The data can serve as a helpful guideline for diagnostic and clinical purposes. Another strong point is its being a cohort and age-related changes can be studies with more validity in the next phases. Nonetheless, longitudinal studies are suggested in different populations, especially on younger samples while the eye undergoes changes.

\section{Conclusions}

In this report, the distribution of $\mathrm{AL}$ and its components are described in a general 40-64 years old Iranian population for the first time. Mean AL in this study, compared to studies conducted [4-12,14-18,20-26,36] in Asia and America, was in the midrange; however, examining its components showed a lower mean ACD and LT. Except for LT which increased with age, all other parameters decrease with age. Also, the studied biometrics were all higher in men compared to women.

\section{Competing interests}

The author declares that they have no competing interests.

\section{Authors' contributions}

$\mathrm{HH}, \mathrm{MHE}, \mathrm{MS}$ and $\mathrm{AF}$ conceived and designed the study and contributed in preparation of the study protocol and were involved in data collection supervision. $\mathrm{HH}, \mathrm{MK}$, and AF participated in study design, performed the statistical analyses and drafted the manuscript. MM, MS and TA contributed in the conceptualization of the paper and the statistical analyses and critically revised the manuscript. All authors read and critically revised the manuscript and approved the final draft.

\section{Acknowledgments}

This project was supported by Noor Ophthalmology Research Center, Shahroud University of Medical Sciences and Tehran University of Medical Sciences. 


\section{Author details}

'Noor Ophthalmology Research Center, Noor Eye Hospital, Tehran, Iran. ${ }^{2}$ Farabi Eye Hospital, Tehran University of Medical Sciences, Tehran, Iran. ${ }^{3}$ Shahroud University of Medical Sciences, Shahroud, Iran. ${ }^{4}$ Department of Community Medicine, School of Medicine, Tehran University of Medical Sciences, Tehran, Iran. ${ }^{5}$ Department of Optometry, Tehran University of Medical Sciences, Tehran, Iran. ${ }^{6}$ Department of Epidemiology and Biostatistics, School of Public Health, Tehran University of Medical Sciences, Tehran, Iran.

Received: 25 October 2011 Accepted: 30 August 2012 Published: 18 September 2012

\section{References}

1. Verhulst E, Vrijghem JC: Accuracy of intraocular lens power calculations using the Zeiss IOL master. A prospective study. Bull Soc Belge Ophtalmol 2001, 281:61-65.

2. Saka N, Ohno-Matsui K, Shimada N, Sueyoshi S, Nagaoka N, Hayashi W, Hayashi K, Moriyama M, Kojima A, Yasuzumi K, et al: Long-term changes in axial length in adult eyes with pathologic myopia. Am J Ophthalmol 2010, 150:562-568.

3. Ruiz-Moreno JM, Montero JA, de la Vega C, Alio JL, Zapater P: Retinal detachment in myopic eyes after phakic intraocular lens implantation. J Refract Surg 2006, 22:247-252.

4. Wickremasinghe S, Foster PJ, Uranchimeg D, Lee PS, Devereux JG, Alsbirk PH, Machin D, Johnson GJ, Baasanhu J: Ocular biometry and refraction in Mongolian adults. Invest Ophthalmol Vis Sci 2004, 45:776-783.

5. Shih YF, Chiang TH, Lin LL: Lens thickness changes among schoolchildren in Taiwan. Invest Ophthalmol Vis Sci 2009, 50:2637-2644.

6. Warrier S, Wu HM, Newland HS, Muecke J, Selva D, Aung T, Casson RJ: Ocular biometry and determinants of refractive error in rural Myanmar: the Meiktila Eye Study. Br J Ophthalmol 2008, 92:1591-1594.

7. Wong TY, Foster PJ, Ng TP, Tielsch JM, Johnson GJ, Seah SK: Variations in ocular biometry in an adult Chinese population in Singapore: the Tanjong Pagar Survey. Invest Ophthalmol Vis Sci 2001, 42:73-80.

8. He M, Huang W, Li Y, Zheng Y, Yin Q, Foster PJ: Refractive error and biometry in older Chinese adults: the Liwan eye study. Invest Ophthalmol Vis Sci 2009, 50:5130-5136.

9. Mallen EA, Gammoh Y, Al-Bdour M, Sayegh FN: Refractive error and ocular biometry in Jordanian adults. Ophthalmic Physiol Opt 2005, 25:302-309.

10. Osuobeni EP: Ocular components values and their intercorrelations in Saudi Arabians. Ophthalmic Physiol Opt 1999, 19:489-497.

11. Yekta AA, Fotouhi A, Hashemi H, Moghaddam HO, Heravian J, Heydarian S, Yekta R, Derakhshan A, Rezvan F, Behnia M, et al: Relationship between refractive errors and ocular biometry components in carpet weavers. Iranian Journal of Ophthalmology 2010, 22:45-54.

12. Kolodziejczyk W, Galecki T, Lazicka-Galecka M, Szaflik J: Comparison of the biometric measurements obtained using noncontact optical biometers LenStar LS 900 and IOL Master V. 5. Klin Oczna 2011, 113:47-51.

13. Buckhurst PJ, Wolffsohn JS, Shah S, Naroo SA, Davies LN, Berrow EJ: A new optical low coherence reflectometry device for ocular biometry in cataract patients. Br J Ophthalmol 2009, 93:949-953.

14. Fotedar R, Wang JJ, Burlutsky G, Morgan IG, Rose K, Wong TY, Mitchell P: Distribution of axial length and ocular biometry measured using partial coherence laser interferometry (IOL Master) in an older white population. Ophthalmology 2010, 117:417-423.

15. Logan NS, Davies LN, Mallen EA, Gilmartin B: Ametropia and ocular biometry in a U.K. university student population. Optom Vis Sci 2005, 82:261-266.

16. Wu HM, Gupta A, Newland HS, Selva D, Aung T, Casson RJ: Association between stature, ocular biometry and refraction in an adult population in rural Myanmar: the Meiktila eye study. Clin Experiment Ophthalmol 2007, 35:834-839.

17. Nangia V, Jonas JB, Matin A, Kulkarni M, Sinha A, Gupta R: Body height and ocular dimensions in the adult population in rural Central India. The Central India Eye and Medical Study. Graefes Arch Clin Exp Ophthalmol 2010, 248:1657-1666.

18. Foster PJ, Broadway DC, Hayat S, Luben R, Dalzell N, Bingham S, Wareham $N J$, Khaw KT: Refractive error, axial length and anterior chamber depth of the eye in British adults: the EPIC-Norfolk Eye Study. Br J Ophthalmol 2010, 94:827-830.

19. Shufelt C, Fraser-Bell S, Ying-Lai M, Torres M, Varma R: Refractive error ocular biometry, and lens opalescence in an adult population: the Los Angeles Latino Eye Study. Invest Ophthalmol Vis Sci 2005, 46:4450-4460.

20. Jivrajka R, Shammas MC, Boenzi T, Swearingen M, Shammas HJ: Variability of axial length, anterior chamber depth, and lens thickness in the cataractous eye. I Cataract Refract Surg 2008, 34:289-294.

21. Velez-Montoya R, Shusterman EM, Lopez-Miranda MJ, Mayorquin-Ruiz M, Salcedo-Villanueva G, Quiroz-Mercado H, Morales-Canton V: Comparison of the biometric values obtained by two different A-mode ultrasound devices (Eye Cubed vs. PalmScan): a transversal, descriptive, and comparative study. BMC Ophthalmol 2010, 10:8.

22. Xu L, Cao WF, Wang YX, Chen CX, Jonas JB: Anterior chamber depth and chamber angle and their associations with ocular and general parameters: the Beijing Eye Study. Am J Ophthalmol 2008, 145:929-936.

23. Hashemi H, KhabazKhoob M, Mehravaran S, Yazdani K, Mohammad K, Fotouhi A: The distribution of anterior chamber depth in a Tehran population: the Tehran eye study. Ophthalmic Physiol Opt 2009, 29:436-442.

24. He M, Huang W, Zheng Y, Alsbirk PH, Foster PJ: Anterior chamber depth in elderly Chinese: the Liwan eye study. Ophthalmology 2008, 115:1286-1290. 1290 e1281-1282.

25. Foster PJ, Alsbirk PH, Baasanhu J, Munkhbayar D, Uranchimeg D, Johnson GJ: Anterior chamber depth in Mongolians: variation with age, sex, and method of measurement. Am J Ophthalmol 1997, 124:53-60.

26. Mutti DO, Mitchell GL, Jones $L A$, Friedman NE, Frane SL, Lin WK, Moeschberger ML, Zadnik K: Axial growth and changes in lenticular and corneal power during emmetropization in infants. Invest Ophthalmol Vis Sci 2005, 46:3074-3080.

27. Gudmundsdottir E, Arnarsson A, Jonasson F: Five-year refractive changes in an adult population: Reykjavik Eye Study. Ophthalmology 2005, 112:672-677.

28. Koretz JF, Neider MW, Kaufman PL, Bertasso AM, DeRousseau CJ, Bito LZ: Slit-lamp studies of the rhesus monkey eye. I. Survey of the anterior segment. Exp Eye Res 1987, 44:307-318.

29. Praveen MR, Vasavada AR, Shah SK, Shah CB, Patel UP, Dixit NV, Rawal S: Lens thickness of Indian eyes: impact of isolated lens opacity, age, axial length, and influence on anterior chamber depth. Eye (Lond) 2009, 23:1542-1548.

30. Bourne RR, Dineen BP, Ali SM, Noorul Huq DM, Johnson GJ: Prevalence of refractive error in Bangladeshi adults: results of the National Blindness and Low Vision Survey of Bangladesh. Ophthalmology 2004, 111:1150-1160.

31. Wu SY, Nemesure B, Leske MC: Refractive errors in a black adult population: the Barbados Eye Study. Invest Ophthalmol Vis Sci 1999, 40:2179-2184

32. Yekta AA, Fotouhi A, Khabazkhoob M, Hashemi H, Ostadimoghaddam H, Heravian J, Mehravaran S: The prevalence of refractive errors and its determinants in the elderly population of Mashhad, Iran. Ophthalmic Epidemiol 2009, 16:198-203.

33. Krishnaiah S, Srinivas M, Khanna RC, Rao GN: Prevalence and risk factors for refractive errors in the South Indian adult population: The Andhra Pradesh Eye disease study. Clin Ophthalmol 2009, 3:17-27.

34. Hashemi H, Khabazkhoob M, Jafarzadehpur E, Yektaa A, Emamian MH, Shariati M, Fotouhi A: High Prevalence of Myopia in an Adult Population, Shahroud, Iran. Optom Vis Sci 2012, 89:993-999.

35. Hashemi H, Fotouhi A, Mohammad K: The age- and gender-specific prevalences of refractive errors in Tehran: the Tehran Eye Study. Ophthalmic Epidemiol 2004, 11:213-225.

36. Eysteinsson T, Jonasson F, Arnarsson A, Sasaki H, Sasaki K: Relationships between ocular dimensions and adult stature among participants in the Reykjavik Eye Study. Acta Ophthalmol Scand 2005, 83:734-738.

doi:10.1186/1471-2415-12-50

Cite this article as: Hashemi et al: The distribution of axial length, anterior chamber depth, lens thickness, and vitreous chamber depth in an adult population of Shahroud, Iran. BMC Ophthalmology 2012 12:50. 